\title{
Effectiveness of Analogs of the GS-Nitroxide, JP4-039, as Total Body Irradiation Mitigators
}

\author{
MICHAEL W. EPPERLY ${ }^{1}$, JOSHUA R. SACHER ${ }^{2,3}$, TANJA KRAINZ ${ }^{2,3}$, XIAOLIN ZHANG $^{2,3}$, PETER WIPF $^{2,3}$, \\ MARY LIANG $^{2,3}$, RENEE FISHER ${ }^{1}$, SONG LI $^{4}$, HONG WANG ${ }^{1}$ and JOEL S. GREENBERGER ${ }^{1}$ \\ ${ }^{1}$ Department of Radiation Oncology, University of Pittsburgh Cancer Institute, Pittsburgh, PA, U.S.A.; \\ ${ }^{2}$ Department of Chemistry, ${ }^{3}$ Center for Chemical Methodologies and Library Development, and \\ ${ }^{4}$ School of Pharmacy, University of Pittsburgh, Pittsburgh, PA, U.S.A.
}

\begin{abstract}
Background/Aim: Mitochondrial-targeted gramicidin S (GS)-nitroxide, JP4-039, has been demonstrated to be a potent radiation mitigator, and safe over a wide dose range. In addition, JP4-039 has organ-specific effectiveness when locally applied. Materials and Methods: We tested the effect of another GS-nitroxide, XJB-5-131, which has more effective mitochondrial localization, and compared these results to those for radiation mitigation against the hematopoietic syndrome, and two analogs of JP4-039, which have the same mitochondrial localization signal, but different chemical payloads: JRS527.084 contains a second nitroxide per molecule, and TK649.030 contains an ester group attached to the nitroxide. Results: The results demonstrate the superiority of JP4-039 as a systemic radiation mitigator. Conclusion: Structure-activity relationships and bioassays demonstrate that JP4-039 is an optimized small-molecule radiation mitigator.
\end{abstract}

Ionizing irradiation damage to cells, tissues, organs, and organ systems has been demonstrated to have several phases, the initial phase being programmed cell death or apoptosis (1-6).

Using mouse models, we previously demonstrated that a mitochondrial-targeted antioxidant and free radical scavenger based on the core nitroxide, 4-amino-Tempo, and targeted to mitochondria by a segment of a cyclopeptide antibiotic, gramicidin $S$ (1, 7-9), was broadly effective against total body irradiation-induced hematopoietic syndrome (10), when drugs are administered before or as late as $72 \mathrm{~h}$ after irradiation $(6,10-17)$.

This article is freely accessible online.

Correspondence to: Joel S. Greenberger, MD, FACRO, FACR, Professor and Chairman, Dept. of Radiation Oncology, University of Pittsburgh Cancer Institute, UPMC Cancer Pavilion, 5150 Centre Avenue, Rm. 533, Pittsburgh, PA 15232, U.S.A. Tel: +1 4126473602, Fax: +1 4126476029, e-mail: greenbergerjs@upmc.edu

Key Words: Oxidative stress, GS-nitroxide, radiation mitigation.
Recently, we demonstrated that the mechanism of radiation mitigation and protecion is due to mitochondrial localization, and abrogation of oxidative stress-mediated events in the mitochondrial membrane (2-4), which led to inhibition of cardiolipin binding to cytochrome $c(16,17)$, and leakage of cytochrome $c$ into the cytoplasm followed by activation of the caspase system and apoptosis $(6,13,14)$. Gramicidin S (GS)-nitroxide, JP4-039, has been shown to be effective when delivered systemically in a novel emulsion F14 $(1,10)$. This emulsion is also effective in ameliorating beta irradiation-induced skin damage (18).

In addition to the effectiveness of JP4-039/F14 delivered systemically or through the skin, a second formulation, F15, has been demonstrated to localize active drug in the oral cavity/oropharynx and significantly ameliorates single-fraction or fractionated irradiation-induced mucositis (19-24).

Previous studies have demonstrated a 30- to 33-fold concentration of 4-amino-Tempo nitroxide at the mitochondria when linked to JP4-039 (14, 15, 23). Another GS-nitroxide, XJB-5-131, has been shown to have a 600-fold mitochondrial concentration in the mitochondria (24), attributable to the longer mitochondrial localization sequence, which was also derived from the natural antibiotic GS.

The mitochondrial-targeted GS-nitroxide, JP4-039, delivered i.v. $24-72 \mathrm{~h}$ after $\mathrm{LD}_{50 / 30}$ total body irradiation (TBI) mitigates irradiation damage (1). To optimize mitochondrial-targeted nitroxide irradiation mitigation, we designed two structurally related, but distinct mitochondrialtargeted nitroxides and compared each with JP4-039, and another GS-nitroxide, XJB-5-131 (24).

In the present studies, we tested whether XJB-5-131 compared to JP4-039 was a TBI mitigator. We also determined whether chemically-synthesized analogs of JP4039, one using the same targeting sequence, but carrying two nitroxides per molecule (JRS527.084) or a prodrug of JP4039 (TK649.030), were equivalent or superior to the lead compound (Figure 1). 
A<smiles>CC(C)C[C@H](/C=C/CC(=O)NC1CC(C)(C)N([O])C(C)(C)C1)N[R6](=O)(=O)O</smiles>

B<smiles>[R4]C(=O)NCCC[C@H](NC(=O)[C@@H](NC(=O)[C@@H]1CCCN1C(=O)[C@H](/C=C/[C@H](CC(C)C)C(=O)O[Na])Cc1ccccc1)C(C)C)C(=O)NC1CC(C)(C)N([O])C(C)(C)C1</smiles><smiles>CC(=O)ON1C(C)(C)CC(NC(=O)C/C=C/[C@@H](CC(C)C)NC(=O)O)CC1(C)C</smiles>

TK649.030

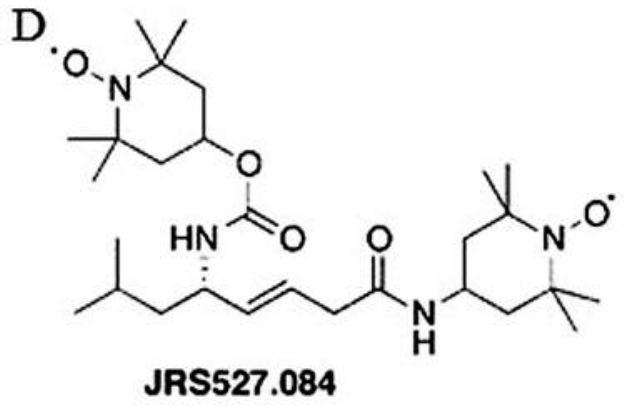

Figure 1. Structure of gramicidin $S$ (GS)-nitroxide radiation mitigators. Small molecules containing 4-amino-Tempo and each of two mitochondrial targeting linkers were constructed: A: JP4-039, B: XJB-5-131, C: ester attached to nitroxide generating an ester pro-drug (TK649-030) and D: new construct with two nitroxides per molecule (JRS527.084).

\section{Materials and Methods}

Drug design and synthesis. JP4-039 and XJB-5-131 contain both a 4-amino-Tempo nitroxide linked to an alkene peptide isostere segment derived from the antibiotic GS (Figure 1). These compounds have proven significant and differential affinity for mitochondria in vivo. XJB-5-131 has a longer peptide-targeting sequence and results in a 600 -fold enrichment in the mitochondria compared to cytoplasm, while JP4-039 contains a shortened alkene dipeptide isostere moiety attached to the nitroxide, which results in a 32-fold enrichment of nitroxide to the mitochondria compared to the cytoplasm (23).

We also tested JRS527.084, which has the identical shortened alkene peptide isostere backbone to that of JP4-039, but with a second nitroxide attached to the allylic amine function. TK649.030 has the same sequence as JP4-039 but is linked to an acetate at the nitroxide oxygen, forming a base-cleavable hydroxylamine/nitroxide prodrug moiety. The synthesis of JP4-039, XJB-5-131, JRS527.084, and TK649.030 has been previously reported (25). The methods for preparation of the formulation of F14 have been published previously $(26,27)$. Briefly, each GS-nitroxide was prepared in $100 \mu$ l volumes of F14 for intravenous injection according to published methods (26, 27). The molarity of each GS-nitroxide analog was calculated to standardize the molarity of drug delivery in a $100 \mu \mathrm{l}$. JP4-039 was formulated at $2 \mathrm{mg} / \mathrm{ml}$, TK649.030 at $2.2 \mathrm{mg} / \mathrm{ml}$, JRS527.084 at $2.5 \mathrm{mg} / \mathrm{ml}$, and XJB-5-131 at $4.0 \mathrm{mg} / \mathrm{ml}$.

Animals, their care and irradiation. C57BL/6NTac female mice (30$33 \mathrm{~g}, 6-8$ weeks old, $\mathrm{n}=15$ per group; Taconic Biosciences, Hudson, NY, USA) were housed four per cage according to Institutional IACUC regulations and fed standard laboratory chow and deionized water (PHS Assurance Number A3187-01).
Mice were irradiated to the radiation dose which killed $50 \%$ of animals at 30 days $\left(\mathrm{LD}_{50 / 30}\right)$ due to death from the hematopoietic syndrome (1) using a gamma cell cesium-137 irradiator (JL Shepherd and Associates, San Fernando, CA USA) at a dose rate of $343 \mathrm{cGy} /$ per minute. The dose rate was increased to $343 \mathrm{cGy} / \mathrm{per}$ minute over the baseline $70 \mathrm{cGy} /$ per minute (according to the manufacturer's specifications) by removing the filter in the irradiator. This resulted in a change in $\mathrm{x}$-ray beam quality with respect to the number of cesium gamma rays in the spectrum.

Mice were irradiated to $9.5 \mathrm{~Gy}$ TBI and injected intravenously $24 \mathrm{~h}$ later with $10 \mathrm{mg} / \mathrm{kg} \mathrm{JP} 4-039 / \mathrm{F} 14$, or equimolar doses of another GS-nitroxide to give the same dose in $100 \mu \mathrm{F} 14$ to provide groups treated with XJB-3-131/F14, JRS527.084/F14, TK649.030/F14, or F14 alone.

Mice were monitored for signs of weakness and weight loss according to Institutional IACUC protocols and were euthanized at the time of loss of $20 \%$ body weight.

Statistical analysis. Calculation of differences in survival after TBI $(n=15$ per group) and the effect of each drug delivered at $24 \mathrm{~h}$ after irradiation were calculated according to previous publication (1).

\section{Results}

The molecular structure of JP4-039 and XJB-5-131 compared to the new test drugs JRS527.084 and TK649.030 are shown in Figure 1. JRS527.084 and TK649.030 were tested for the first time in a radiation model. JRS527.084 has the same GSderived alkene peptide isostere backbone as JP4-039, but twice the nitroxide loading. TK649.030 has an identical backbone structure as JP4-039, but its nitroxide is masked by 


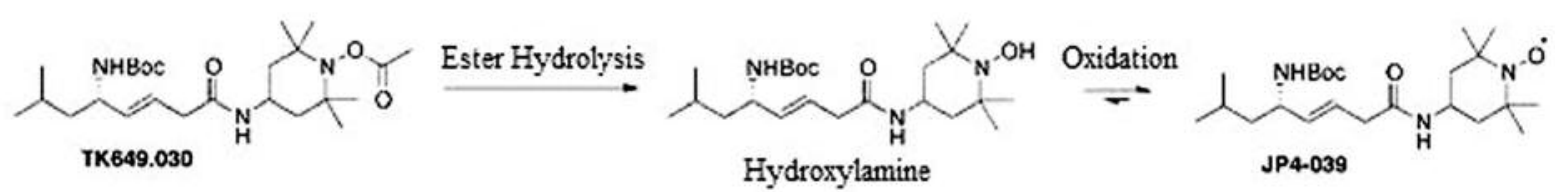

Figure 2. Mechanism of prodrug activation in TK649.030 by ester hydrolysis followed by hydrogen atom abstraction/oxidation of the hydroxylamine to give the nitroxide.
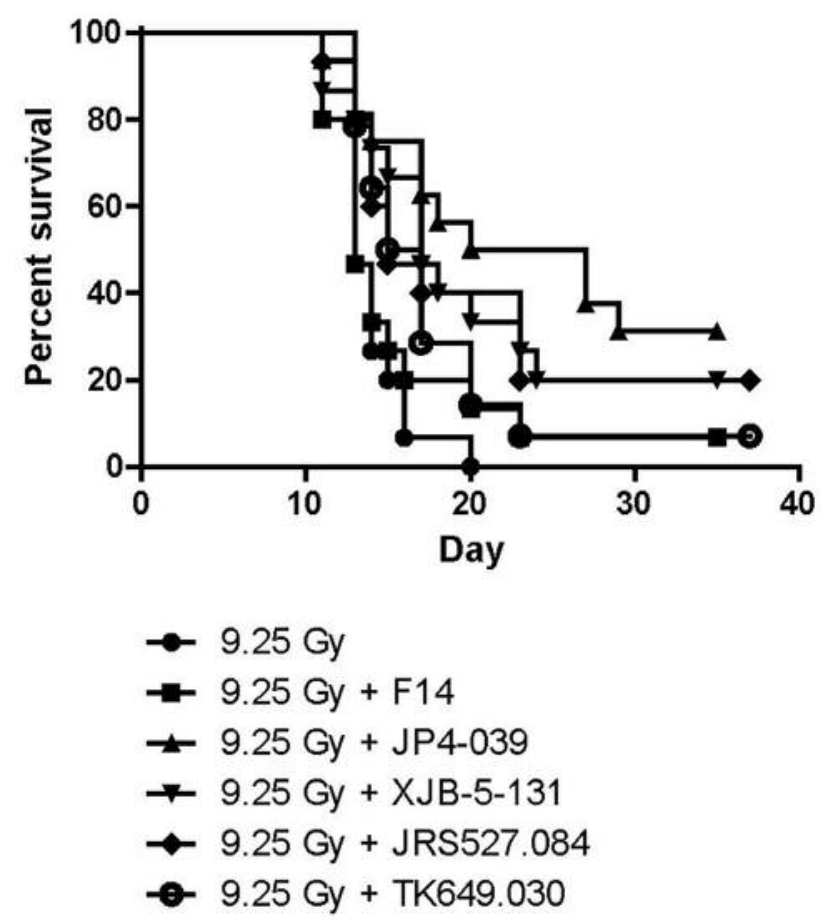

Figure 3. Comparison of each nitroxide for mitigation of the effect of total body irradiation in vivo. JP4-039, XJB-5-131, TK649.030 and JRS527.084 were encapsulated in F14 liposomes (sesame seed oil, soy phosphatidyl choline and Dulbecco's PBS). C57BL/6NTac mice were irradiated to a dose of 9.5 Gy total body irradiation. Twenty-four hours later, the mice were injected i.v. with F14 only, JP4-039/F14, XJB-5-131/F14, TK649.030/F14, or JRS527.084/F14 and followed for the development of hematopoietic syndrome. All four small molecules led to increased survival compared to mice treated with 9.5 Gy alone $(p<0.05)$ (see Table I).

a base-labile ester group that releases the Tempohydroxylamine upon spontaneous hydrolysis or by conversion with a lipase or peptidase. The hydroxylamine is further oxidized to the nitroxide in biological media containing molecular oxygen or other natural redox systems (Figure 2).

Comparison of JP4-039 to other GS-nitroxides as radiation mitigators in vivo. JP4-039 was a highly effective radiation mitigator when delivered at $24 \mathrm{~h}$ after TBI. As shown in Figure 3, comparison of the effect of equimolar
Table I. Effect of gramicidin $S$ (GS)-nitroxides on mitigation of the effect of total body irradiation. Time to median survival (50\%) and the percentage of mice surviving at 35 days after 9.5 Gy were determined. Mice injected with JP4-039/F14 had the greatest probability of increased survival, a median survival of 20 days after irradiation, while all other groups had a median survival of 17 days or less. Mice treated with JP4-039/F14 also had more survivors at 35 days (33\%) compared to the other treatment groups.

\begin{tabular}{|c|c|c|}
\hline $\begin{array}{l}\text { Treatment group } \\
(\mathrm{n}=15 / \text { group })\end{array}$ & $\begin{array}{l}\text { Median survival } \\
\text { (days) }\end{array}$ & $\begin{array}{c}\text { Survival at } 35 \text { days } \\
\text { after } 9.5 \text { Gy }(\%)\end{array}$ \\
\hline $9.5 \mathrm{~Gy}$ & 13 & 0 \\
\hline $9.5 \mathrm{~Gy}+\mathrm{F} 14$ & 14 & $\begin{array}{c}2.2 \\
p=0.1544 v s .9 .5 \mathrm{~Gy}\end{array}$ \\
\hline 9.5 Gy + JP4-039/F14 & 20 & $\begin{array}{c}33 \\
p=0.0003 \text { vs. } 9.5 \mathrm{~Gy} \\
p=0.0027 \text { vs. F14 }\end{array}$ \\
\hline $9.5 \mathrm{~Gy}+\mathrm{XJB}-5-131 / \mathrm{F} 14$ & 17 & $\begin{array}{c}20 \\
p=0.0017 \text { vs. } 9.5 \mathrm{~Gy} \\
p=0.0343 \text { vs. F14 }\end{array}$ \\
\hline 9.5 Gy + TK649.030/F14 & 15 & $\begin{array}{c}6.6 \\
p=0.0058 v s .9 .5 \mathrm{~Gy} \\
p=0.0547 v s . \mathrm{F} 14\end{array}$ \\
\hline 9.5 Gy + JRS527.084 & 17 & $\begin{array}{c}20 \\
p=0.0051 \text { vs. } 9.5 \mathrm{~Gy} \\
p=0.0800 \text { vs. } \mathrm{F} 14\end{array}$ \\
\hline
\end{tabular}

concentrations of each of the four GS-nitroxides also showed JP4-039 to be the superior mitigator.

Compared to mice treated with 9.5-Gy irradiation only, each nitroxide demonstrated significant mitigation. There was no significant mitigation by F14 alone ( $p=0.1544$ for F14 alone, 0.0003 for JP4-039/F14, 0.0017 for XJB-5-131/F14, 0.0058 for JRS527.084/F14, and 0.0051 for TK649.030/F14). There were no significant differences between the four nitroxides; however, JP4-039 led to the best median survival (Table I).

\section{Discussion}

Mechanism of JP4-039 mitigation. The mitochondrialtargeted nitroxides tested in this study all mitigate irradiation damage to different extents. In the absence of significant additional mitigation by the three new GS-nitroxides, the 
development of the small molecule, JP4-039, as a radiation mitigator will be initiated. A possible explanation for the observed superior effects of JP4-039 vs. the more highly mitochondrially targeted XJB-5-131 is that radiation damage requires the presence of significant quantities of mitigator both in the cytosol as well as in mitochondria, a requirement that puts the almost exclusively mitochondrial-targeting XJB-5-131 at a disadvantage. Furthermore, the removal of the prodrug function from TK649.030 might not be sufficiently fast to rival the effective concentration of JP4039. Finally, we hypothesize that due to the additional nitroxide moiety in JRS527.084 and the accompanying loss of the Boc-group on the allylic amine, this compound has a greater translocation into the mitochondria than JP4-039, and consequently a lower effective concentration in the cytosol, but this hypothesis remains to be experimentally verified. Alternatively, the observed effects could be due to differential in vivo absorption, distribution, metabolism, and excretion properties of these analogs.

The present data support moving forward with JP4-039 as our lead compound for drug development of a mitigator for the acute radiation syndrome (hematopoietic failure after TBI).

\section{Conflicts of Interest}

MWE, PW, and JSG have been awarded a United States Patent for the use of Mitochondrial Targeted Nitroxide Agents as Radiation Mitigators.

\section{Acknowledgements}

Supported by NIAID/NIH U19-A1068021. This project used the UPCI animal facility that is supported in part by award P30CA047904.

\section{References}

1 Rwigema J-CM, Beck B, Wang W, Doemling A, Epperly MW, Shields D, Franicola D, Dixon T, Frantz M-C, Wipf P, Tyurina Y, Kagan VE, Wang H and Greenberger JS: Two strategies for the development of mitochondrial-targeted small molecule radiation damage mitigators. Int J Radiat Oncol Biol Phys 80(3): 860-868, 2011.

2 Epperly MW, Gretton JE, Bernarding M, Nie S, Rasul B and Greenberger JS: Mitochondrial localization of copper/zinc superoxide dismutase $(\mathrm{Cu} / \mathrm{ZnSOD})$ confers radioprotective functions in vitro and in vivo. Radiat Res 160: 568-578, 2003.

3 Epperly MW, Bray JA, Esocobar P, Bigbee WL, Watkins S and Greenberger JS: Overexpression of the human MnSOD transgene in subclones of murine hematopoietic progenitor cell line 32D cl 3 decreases irradiation-induced apoptosis, but does not alter $\mathrm{G}_{2} / \mathrm{M}$ or $\mathrm{G}_{1} / \mathrm{S}$ phase cell-cycle arrest. Radiat Oncol Invest Clinical \& Basic Res 7: 331-342, 1999.

4 Epperly MW, Sikora C, Defilippi S, Gretton J, Zhan Q, Kufe DW and Greenberger JS: MnSOD inhibits irradiation-induced apoptosis by stabilization of the mitochondrial membrane against the effects of SAP kinases p38 and JNK1 translocation. Radiat Res 157: 568-577, 2002.
5 Tyurin VA, Tyurina YY, Kochanek PM, Hamilton R, DeKosky ST, Greenberger JS, Bayir $\mathrm{H}$ and Kagan VE: Oxidative lipidomics of programmed cell death. Methods in Enzymology, Chapter 19, 442: 375-393, 2008.

6 Tyurina YY, Tungekar MA, Jung M-Y, Tyurin VA, Greenberger JS, Stoyanovsky DA and Kagan VE: Mitochondria targeting of non-peroxidizable triphenylphosphonium conjugated oleic acid protects mouse embryonic cells against apoptosis: role of cardiolipin remodeling. FEBS Lett 586: 235-241, 2012.

7 Jiang J, Kurnikov I, Belikova NA, Xiao J, Zhao Q, Vlasova IL, Amoscato AA, Braslau R, Studer A, Fink MP, Greenberger JS, Wipf $P$ and Kagan VE: Structural requirements for optimized delivery, inhibition of oxidative stress and anti-apoptotic activity of targeted nitroxides. J Pharmacol Exp Ther 320(5): 1050-1060, 2007.

8 Fink MP, Macias CA, Xiao J, Tyurina YY, Delude RL, Greenberger JS, Kagan VE and Wipf P: HemigramicidinTEMPO Conjugates: Novel mitochondria-targeted antioxidants. Biochem Pharmacol 74: 801-809, 2007.

9 Jiang J, Belikova NA, Xiao J, Zhao Q, Greenberger JS, Wipf $\mathrm{P}$ and Kagan VE: A mitochondria-targeted nitroxide/hemigramicidin S conjugate protects mouse embryonic cells against $\gamma$-irradiation. Int J Radiat Oncol Biol Phys 70(3): 816-825, 2008.

10 Goff JP, Epperly MW, Shields D, Wipf P, Dixon T and Greenberger JS: Radiobiologic effects of GS-nitroxide (JP4-039) in the hematopoietic syndrome. In Vivo 25: 315-324, 2011.

11 Stoyanovsky DA, Huang Z, Jiang J, Belikova NA, Tyurin V, Epperly MW, Greenberger JS, Bayir H and Kagan VE: A manganese-porphyrin complex decomposes hydrogen peroxide, compartmentalizes into mitochondria, inhibits apoptosis and acts as a radiation mitigator in vivo. J. ACS Med Chem Lett 362: 2134, 2011.

12 Bernard ME, Kim H, Berhane H, Epperly MW, Franicola D, Zhang X, Houghton F, Shields D, Wang H, Bakkenist CJ, Frantz M-C, Wipf P and Greenberger JS: GS-nitroxide (JP4-039) mediated radioprotection of human Fanconi anemia cell lines. Radiat Res 176: 603-612, 2011.

13 Atkinson J, Kapralov AA, Yanamala N, Pearce L, Peterson J, Tyurina YY, Epperly MW, Huang Z, Jiang J, Maeda A, Feng W, Wasserloos K, Belikova NA, Tyurin VA, Fletcher J, Wang Y, Vlasova II, Klein-Seetharaman J, Stoyanovsky DA, Bayir H, Pitt BR, Greenberger JS and Kagan VE: A mitochondria-targeted inhibitor of cytochrome $c$ peroxidase mitigates radiation-induced death. Nature Communications 2: 497, 2011.

14 Greenberger JS, Kagan V, Bayir H, Lazo J, Wipf P, Li S, Gao X, Clump D and Epperly MW: Mitochondria-targeted small molecule radiation protectors and radiation mitigators. Front Oncol 1 (article 59): 1-12, 2012.

15 Greenberger JS, Berhane H, Shinde A, Rhieu BH, Bernard M, Wipf P, Skoda EM and Epperly MW: Can radiosensitivity associated with defects in DNA repair be overcome by mitochondrial-targeted antioxidant radioprotectors? Front Oncol 4: 24, (PMC3926189), 2014.

16 Kagan VE, Tyurina YY, Bayir H, Chu CT, Kapralov AA, Vlasova II, Belikova NA, Tyurin VA, Amoscato A, Epperly M, Greenberger J, DeKosky S, Shvedova AA and Jiang J: The "proapoptotic genes" get out of mitochondria: Oxidative lipidomics and redox activity of cytochrome c/cardiolipin complexes. Chem Biol Interact 163: 15-28, 2006 
17 Kagan VE, Bayir A, Bayir H, Stoyanovsky D, Borisenko GG, Tyurina YY, Wipf P, Atkinson J, Greenberger JS, Chapkin RS and Belikova NA: Mitochondria-targeted disruptors and inhibitors of cytochrome c/cardiolipin peroxidase complexes: A new strategy in anti-apoptotic drug discovery. Mol Nutr Food Res 53: 104-114, 2009.

18 Brand R, Epperly MW, Stottlemyer JM, Skoda E, Gao X, Li S, Huq S, Wipf P, Kagan VE, Greenberger JS and Falo LD Jr.: A topical mitochondria targeted antioxidant mitigates oxidative stress induced skin damage. J Invest Dermatol, PII:S0022202X(16)32536-2, DOI:10.1016/j.jid.2016.09.033,2016.

19 Berhane H, Shinde A, Kalash R, Xu K, Epperly MW, Goff J, Franicola D, Zhang X, Dixon T, Shields D, Wang H, Wipf P, Li S, Gao X and Greenberger JS: Amelioration of irradiationinduced oral cavity mucositis and distant bone marrow suppression in Fancd2 ${ }^{-/}(\mathrm{FVB} / \mathrm{N})$ mice by intraoral JP4039/F15. Radiat Res 182: 35-49, 2014.

20 Shinde A, Berhane H, Rhieu BH, Kalash R, Xu K, Goff J, Epperly MW, Franicola D, Zhang X, Dixon T, Shields D, Wang H, Wipf P, Parmar K, Ferris R, Li S and Greenberger JS: Intraoral mitochondrial-targeted GS-nitroxide, JP4-039, radioprotects normal tissue in tumor-bearing radiosensitive Fancd2-/- (C57BL/6) mice. Radiat Res 185: 134-150, 2016.

21 Epperly MW, Rwigema J-CM, Li S, Gao X, Wipf P, Goff J, Wang H, Franicola D, Shen H, Kagan V, Bernard M and Greenberger JS: Intraesophageal administration of GS-nitroxide (JP4-039) protects against ionizing irradiation-induced esophagitis. In Vivo 24(6): 811-821, 2010.

22 Epperly MW, Goff JP, Franicola D, Wang H, Wipf P, Li S and Greenberger JS: Esophageal radioprotection in thoracicirradiated mice with transgenic lung tumors by swallowed JP4039/.F15. In Vivo 28: 435-550, 2014.
23 Frantz M-C, Skoda EM, Sacher JR, Epperly MW, Goff JP, Greenberger JS and Wipf P: Synthesis of analogs of the radiation mitigator JP4-039 and visualization of BODIPY derivatives in mitochondria. Org Biomol Chem 11: 4147-4153, 2013.

24 Ji J, Kline AE, Amoscato A, Samhan-Arias AK, Sparvero LJ, Tyurin VA, Tyurina YY, Fink B, Manole MD, Puccio AM, Okonkwo DO, Cheng JP, Alexander H, Clark RS, Kochanek PM, Wipf P, Kagan VE and Bayir H: Lipidomics identifies cardiolipin oxidation as a mitochondrial target for redox therapy of brain injury. Nature Neuroscience 15(10): 1407-1413, 2012.

25 Krainz T, Gaschler MM, Lim C, Sacher JR, Stockwell BR and Wipf P: A mitochondrial-targeted nitroxide is a potent inhibitor of ferroptosis. ACS Cent Sci 2: 653-659, 2016.

26 Goff JP, Epperly MW, Shields D, Wipf P, Dixon T and Greenberger JS: Radiobiologic effects of GS-nitroxide (JP4-039) in the hematopoietic syndrome. In Vivo 25: 315-324, 2011.

27 Gao X, Huang Y, Makhov AM, Epperly M, Lu J, Grab S, Zhang P, Rohan L, Wipf P, Greenberger J and Li S: Nanoassembly of surfactants with interfacial drug-interactive motifs as tailordesigned drug carriers. Mol Pharmacol 10(1): 187-198, 2013.

Received November 7, 2016

Revised December 5, 2016

Accepted December 8, 2016 